\title{
Mesenchymal stem cells - a promising perspective in the orofacial cleft surgery
}

\author{
Stanko $\mathrm{P}^{1}$, Mracna $\mathbf{J}^{1}$, Stebel $\mathrm{A}^{1}$, Usakova $\mathrm{V}^{2}$, Smrekova $\mathrm{M}^{3}$, Vojtassak $\mathbf{J}^{2,3}$ \\ Department of Stomatology and Maxillofacial Surgery, Faculty of Medicine, Comenius University and \\ St Elisabeth Hospital, Bratislava, Slovakia. pstanko@ousa.sk
}

\begin{abstract}
Autologous bone grafts provide the golden standard for closure of oronasal fistulas in the cleft palate. Augmentation may be performed also by homografts and various xenogenic or alloplastic materials to prevent morbidity at the donor site but they may cause many problems (transmission of infections, immune response etc.). All the mentioned approaches also often reveal recurrences of the fistulas and prolong suffering of the cleft patients. Combination of mesenchymal stem cells (MSCs) and so called "platelet gel" seems to be a perspective method in this way. The platelet gel contains hydroxyapatite particles mixed with platelet rich plasma coagulated under effect of the calcium ions. The MSCs from the pelvic bone marrow aspirate are cultivated on a scaffold (collagen membrane) for 3-4 weeks before placement into the cleft defect. The method provides promising results in the alveolar clefts. Authors document a successful case of the secondary surgery in 25-year-old man with the unilateral complete cleft (Fig. 5, Ref. 10). Full Text in PDF www.elis.sk.

Key words: cleft palate, oronasal fistula, mesenchymal stem cells, platelet rich plasma, hydroxyapatite.
\end{abstract}

Complete clefts of lip, alveolus and palate include repaire of the lip as soon as possible, closure of the soft palate between 18 and 24 months of age and correction of the hard palate until maxillary growth is finished at ages 11 to 13 years. Removable obturators can be worn in the meantime to partition of the oral and nasal cavities (1). However, in many cases this is not the end of the surgery because the patients require further secondary corrections of the lip/nasal aesthetics (task for plastic surgeons) and suffer for many years from recurrences of the residual oronasal fistulas especially in alveolar process of the maxilla (task for maxillofacial surgeons). Causes of failure of the primary closure of the alveolar defects include mucosa and bone problems. The mucosa complications comprise dehiscence of the wound edges on the nasal or oral surface due to insufficient amount of the soft tissues consumpted within the primary surgery. The subsequent traction and ischemia of the wound edges leads to opening, infection of the bone defect and

${ }^{1}$ Department of Stomatology and Maxillofacial Surgery, Faculty of Medicine, Comenius University, Bratislava, Slovakia, ${ }^{2}$ Internal Oncogical Department, St Elisabeth Hospital, Bratislava, Slovakia, ${ }^{3}$ II Department of Radiology, Faculty of Medicine, Comenius University and St Elisabeth Hospital, Bratislava, Slovakia, ${ }^{4}$ Faculty of Health and Social Work, Trnava University, Trnava, Slovakia, and ${ }^{5}$ Institute of Medical Biology, Genetics and Medical Genetics, Faculty of Medicine, Comenius University, Bratislava, Slovakia

Address for correspondence: P. Stanko, MD, PhD, Dept of Stomatology and Maxillofacial Surgery, Comenius University and St Elisabeth Hospital, Heydukova 10, SK-812 50 Bratislava, Slovakia.

Phone: +421.2.59249742, Fax: +421.2.59249724

Acknowledgements: Supported by the Grant of Ministry of Health of Slovak Republic No. 2007/36-UK-07. All authors have declared no conflict of interest. subsequent recurrence of the fistula. Beside these more technical problems of the mucosa also biological quality of the bone plays importnat role in the surgery failure. There is present decreased tendency for healing due to congenital lowered quality of the tissue mainly originating in the poor activity of the bone progenitor cells and in the compromised blood supply. Though closure of the bone defects does not require concept of mechanical filling of the empty space in the fistula with any material in sufficient volume but also in an adequite biological quality.

Autologous bone grafts provide the golden standard for the procedure in form of chips or blocks. They do not have any antigenic properties and contain vital progenitor cells with osteogenic and osteoinductive effects, to disadvantages of the autografts belong morbidity in the donor site and absorption in about $60 \%$ of volume within the first year. Homografts from human cadavers or living donors threaten with risk of transmission of infections (especially the human immunodeficiency virus, hepatitis B and C), heterografts of the animal origin may have antigenic properties, although recently improved by progressive technologies to a minimal level (2). Augmentation of the alveolar ridge in area of the cleft may be performed also by various alloplastic bone substitute ceramic-based materials as well as polymers or others to prevent morbidity at the donor site and loss of the tissue volume $(3,4)$. Their disadvantages are increased cost and only osteocondutive effect due to absence of the vital cells. The second disadvantage may be solved by addition of some growth factors of the bone morphogenic proteins (BMP) group or those factors present in the platelet rich plasma (PRP).

At our workplace the Ethical Commettee of the Faculty of Medicine, Comenius University in Bratislava approved combined method of the mesenchymal stem cells (MCSs) and so called 


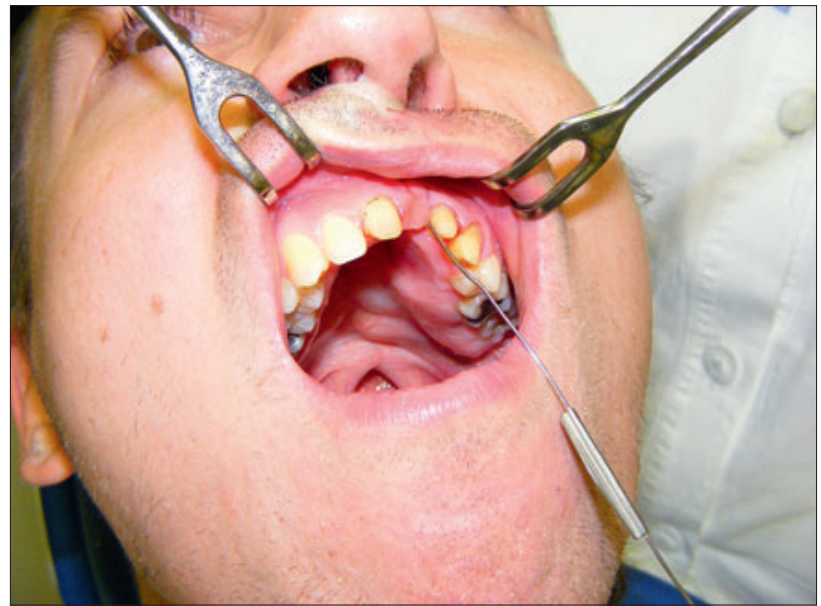

Fig. 1. An oronasal fistula at the mesial aspect of the lateral left upper incisor 22 detected by means of a blunt probe.

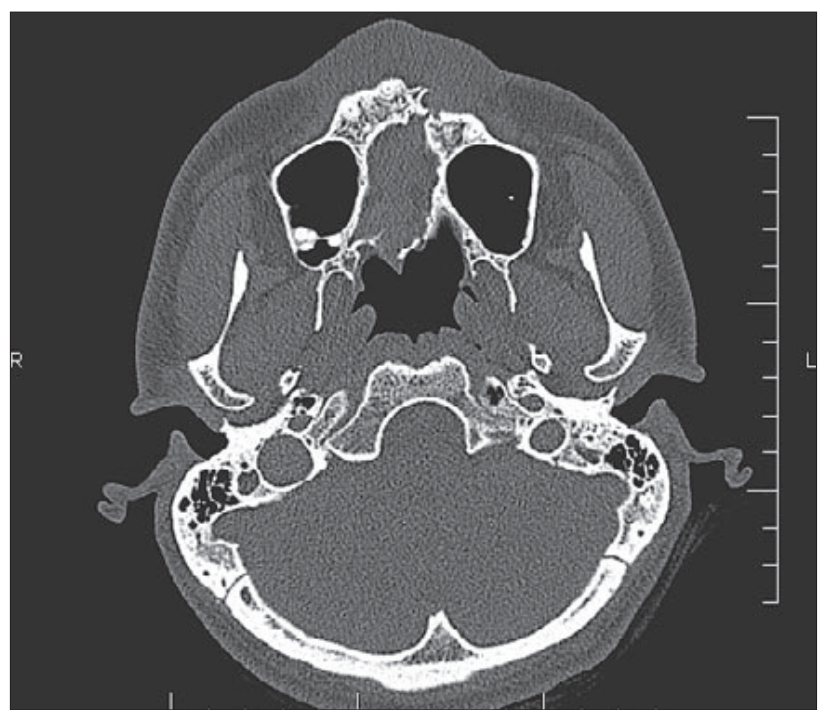

Fig. 2. The CT scan before treatment showing the oronasal fistula.

"platelet gel" for use in bone augmentations including the secondary alveolar cleft surgery.

The MCSs are harvested from bone marrow aspirate from crista iliaca, their cultivation is realized in the Institute of Medical Biology, and the operations are carried out in the Department of Stomatology and Maxillofacial Surgery.

Concept of the method combines advantages of the hydroxyapatite as building material for the bone tissue, growths factors from the PRP as mediators of the bone regeneration $(5,6)$ and the MSCs as active osteogenesis "workers" in the site of surgically refreshed oronasal fistula $(7,8)$. The collagen membrane with cultivated MSCs does not work as an occlusive barrier in the guided bone regeneration but only as a scaffold of the MSCs (9). We demonstrate our concept on a successful case.

A 25-year-old man with history of multiple operations due to an unilateral complete cleft on the left side performed in another hospitals visited our Department of Stomatology and Maxillofa-

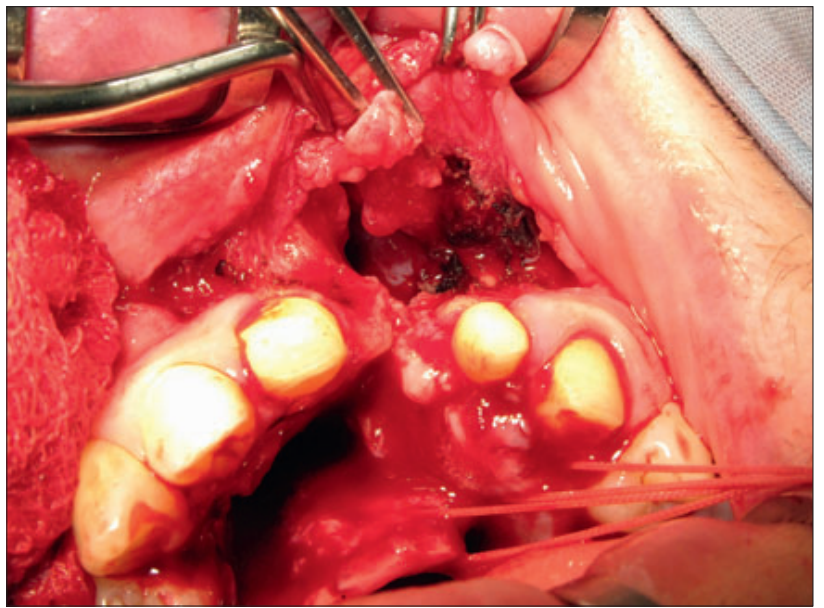

Fig. 3. An peroperative view of the defect after curretage of the epithelial layer along with soft wall of the oronasal fistula.

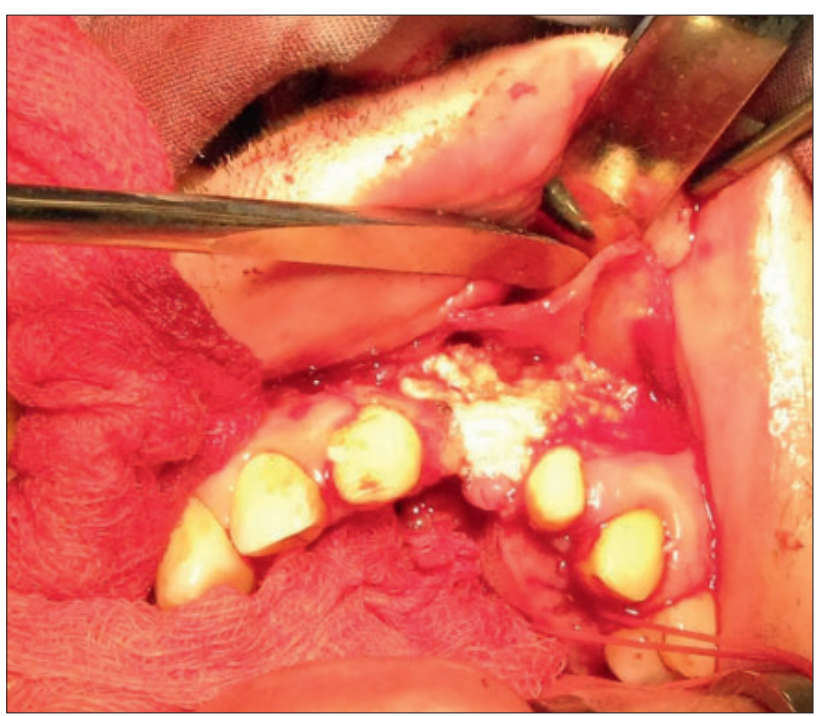

Fig. 4. The collagen membrane with MSCs placed into the wound together with so called platelet gel (mixture of the hydroxyapatite particles and the PRP).

cial Surgery with request of new surgery. At presentation he complained about occasional leak of fluids from the nose and milde speech problems because of air loss by pronunciation of letters "s" and "f". The gap in site of the missing first left upper incisor 21 was treated with a fixed bridge four years earlier. Objectively both direct and indirect Valsalv's maneuvers revealed positivity (10) and with removal of the bridge a residual oronasal fistula was detected at the mesial aspect of the left lateral incisor (Fig. 1). The CT scans provided more exact imaging of the fistula (Fig. 2). After the decision for new surgery a detailed illumination of both the MSCs harvesting/cultivation and the surgical phases of the treatment followed and the patient signed the informed consent.

The MSCs were harvested by aspiration of $10 \mathrm{ml}$ of the bone marrow with Jamshidi's needle from crista iliaca under aseptic conditions and local anaesthesia on an out-patient basis. The as- 


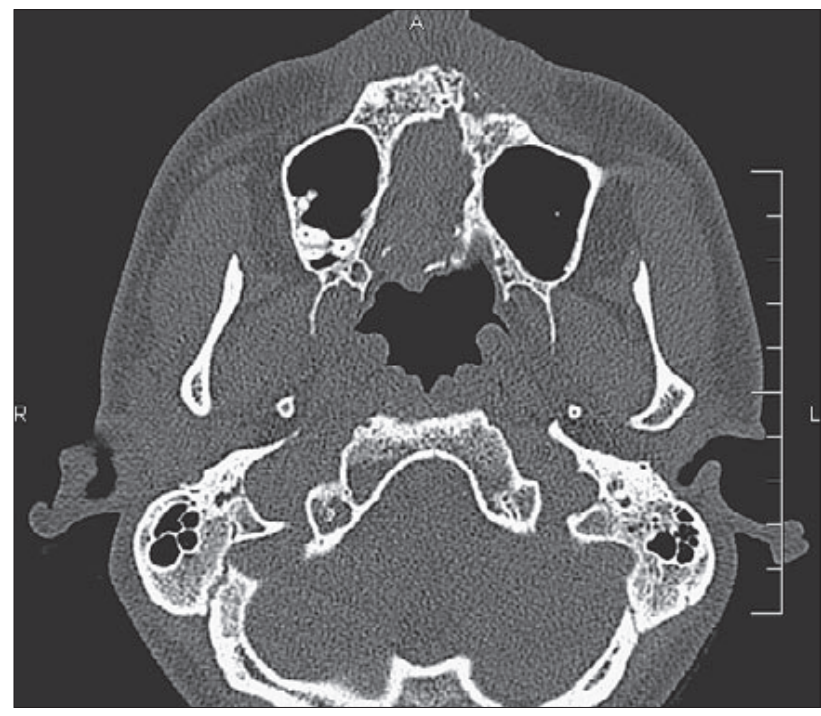

Fig. 5. The CT scan ten weeks after the operation with an inicial bone formation in the site of the oronasal fistula.

pirated material instillated into precooled test tube with special solution was immediately transported under cool conditions and adjusted in the biolab. The cultivation phase with spontanneous differentiation of the MCSs on an absorbable collagen membrane (Coladerm) lasted for three weeks under the biologist's regular control. After this period the operation was performed under general anaesthesia with orotracheal intubation. Collection of 5 $\mathrm{ml}$ of venous blood for the PRP prepare preceded the surgery. Two oblique releasing vestibular incisions were done in region of the central right incisor 11 and the lateral left incisor 22. By transpapilary palatal incision within the first upper molars mucoperiosteal flaps were developed on both the oral and the vestibular surfaces of the maxillary crest. After curretage of the epithelial layer along with soft wall of the canal the oronasal fistula led by the incisor 22 into $10 \times 7 \mathrm{~mm}$ large defect on the nasal floor (Fig. 3 ) where the mucosa was sutured in separate nasal layer. At the moment the MSCs scaffold (collagen membrane) was adjusted to proper size and placed into the wound. Within the time sufficient amount (approximately 2 grams) of the hydroxyapatite particles sized 0.5 milimeters in the diameter and $1.5 \mathrm{ml}$ of the PRP were mixed together, thereafter $10 \%$ calcium gluconate solution was added to start coagulation of the two components and get the so called "platelet gel". The mixation was carried out with a plastic spatule during about two minutes till achievement of the proper gelatinous consistency. This material was layed down on the collagen membrane with MSCs to fill the defect completely (Fig. 4) and then overlayed with the mucoperiosteal flap. Finally after the wound suture suspension of 3.0 million MSCs and the rest of the PRP were applied into the filled defect transmucousally. Postoperatively antibiotics (Clindamycin $300 \mathrm{mg}$ i. v. every 8 hours) were administred for 5 days and the patient was dimissed from the hospital after one week without complications. The CT scan ten weeks after the operation revealed the inicial bone formation in the site of the oronasal fistula (Fig. 5). Because the fistula disapeared also clinically and the both Valsalv's maneuvers were negative, the fixed bridge was inserted after three moths in the original position by means of a dental phosphate cement. The patient is planned for long-term follow-up.

\section{References}

1. Peterson LJ, Ellis E, Hupp JR, Tucker MR. Contemporary oral and maxillofacial surgery. 3rd edition. St Luis; Mosby, 1998.

2. Naujoks C, Langenbach F, Berr K, Depprich R, Kubler N, Meyer U, Handschel J, Kogler G. Biokompatibility of osteogenic predifferentiated human cord stem cells with biomaterials and the influence of the biomaterials on the process of differentiation. J Biomat Appl 2011; 25: 497-512.

3. Nkenke E, Weisbach V, Winckler E, Kessler P, Schultze-Mosgau S, Wiltfang J, Neukam F. Morbidity of harvesting of bone grafts from the iliac crest for preprosthetic augmentation procedures - a prospective study. Int J Oral Maxillofac Surg 2004; 33: 157-163.

4. Kao S, Scott D. A review of bone substitues. Oral Maxillofac Surg Clin North Am 2007; 19: 513-521.

5. Ulicna M, Danisovic L, Vojtassak J. Does cell therapy and tissue engineering represent a promising treatment of diabetic foot ulcers? Bratisl Med J 2010; 111 (3): 138-143.

6. Feltsan T, Mracna J, Holly D. Use of thrombocyte concentrates in treatment of bone defects. Bratisl Med J 2011; 112 (11): 655-657.

7. Andrew JL, Grande DA. Mesenchymal Stem Cells in Tissue Engineering. Cells Tissues Organs 2006; 183: 112-122.

8. Caplan AI. Adult mesenchymal stem cells for tissue engineering versus regenerative medicine. J Cell Physiol 2007; 213 (2): 341-347.

9. Gimbel M, Ashley RK, Sisodia M, Gabbay JS, Wasson KL, Heller J, Wilson L, Kawamoto HK, Bradley JP. Repair of alveolar cleft defects: reduced morbidity with bone marrow stem cells in a resorbable matrix. J Craniofac Surg 2007; 18 (4): 895-901.

10. Stanko P, Poruban D, Novotnakova D, Holly D. Dentoalveolar and Maxillofacial Surgery. 1st edition. Bratislava; Comenius University Press, 2011. 